\title{
Selective detection of carbon monoxide on p-block doped monolayers of $\mathrm{MoTe}_{2}$
}

\author{
Maciej J. Szary, ${ }^{*}$ Dominik M. Florjan, and Jakub A. Bąbelek \\ Institute of Physics, Poznan University of Technology, ul. Piotrowo 3, 61-138 Poznan, \\ Poland \\ E-mail: maciej.szary@put.poznan.pl
}


(a)

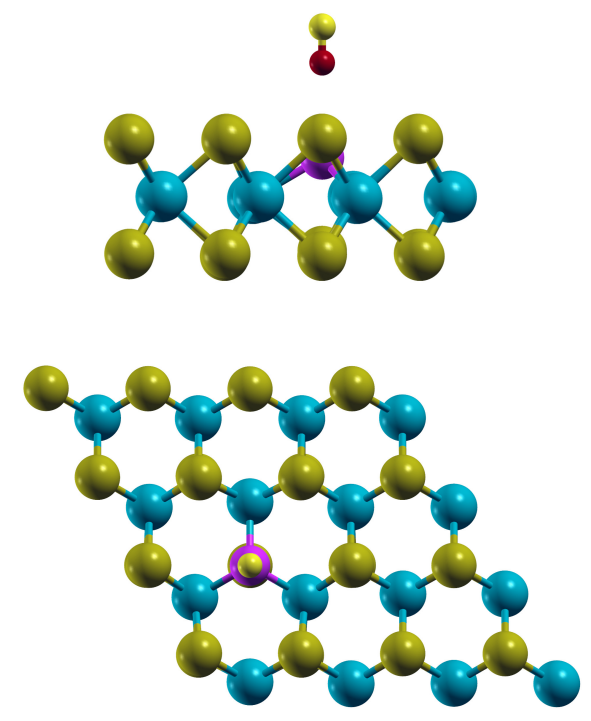

(c)

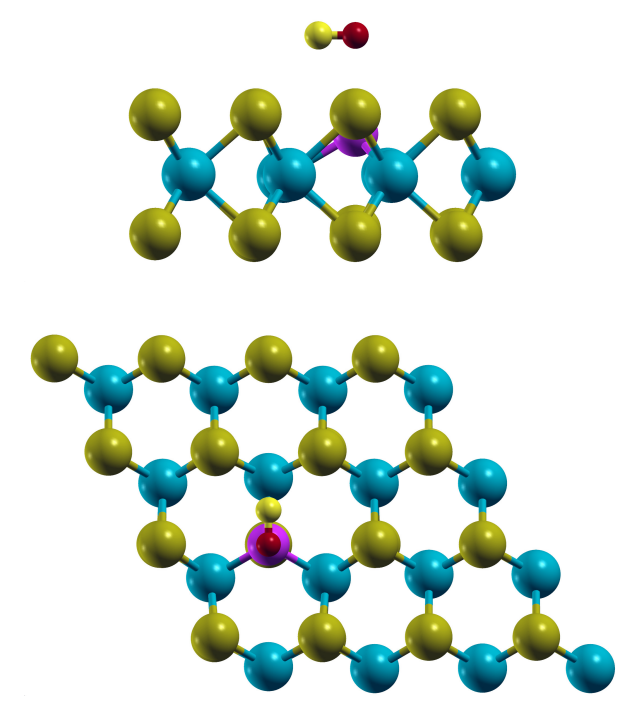

(b)

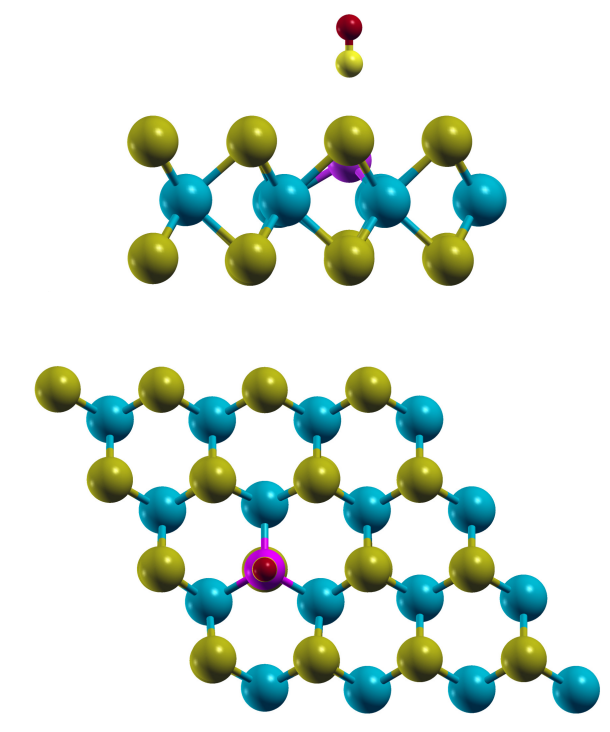

(d)
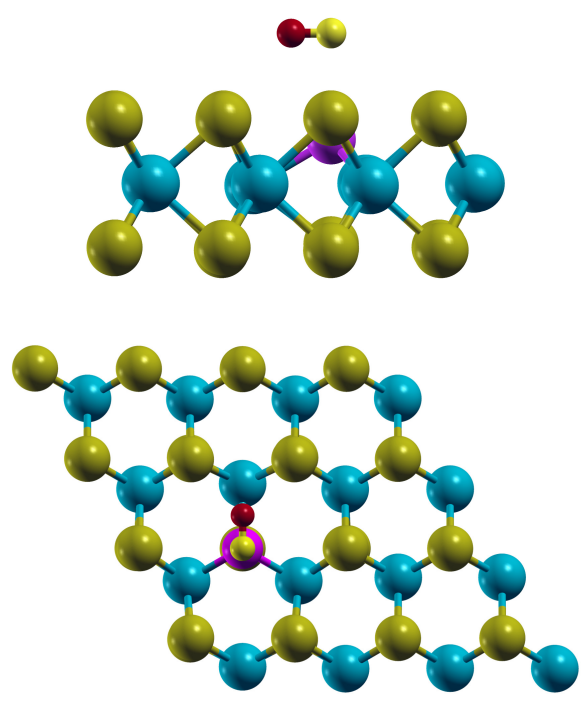

Figure S1: Initial configurations of CO before relaxation: (a) vertical O over the dopant (vert-O), (b) vertical C over the dopant (vert-C), (c) horizontal O over the dopant (horiz-O), and (d) horizontal C over the dopant (horiz-C).

Table S1: Work functions and band gaps of $\mathrm{CO}_{2} @ \mathrm{MoTe}_{2}$ and CO@X-MoTe 2

\begin{tabular}{ccc}
\hline & work function $(\mathrm{eV})$ & band gaps $(\mathrm{eV})$ \\
\hline $\mathrm{MoTe}_{2}$ & 4.590 & 1.05 \\
$\mathrm{Al}-\mathrm{MoTe}_{2}$ & 4.647 & metallic \\
$\mathrm{Si}-\mathrm{MoTe}_{2}$ & 4.571 & 0.83 \\
$\mathrm{P}-\mathrm{MoTe}_{2}$ & 4.884 & 0.90 \\
$\mathrm{~S}-\mathrm{MoTe}_{2}$ & 4.587 & 0.97 \\
$\mathrm{Cl}-\mathrm{MoTe}_{2}$ & 4.329 & metallic \\
\hline
\end{tabular}


(a)

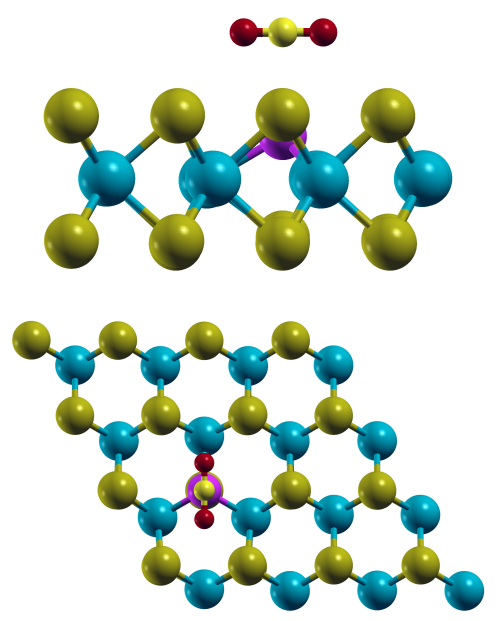

(b)

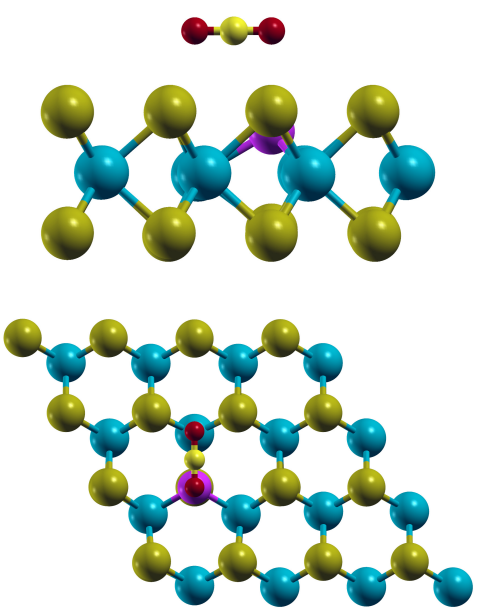

(c)

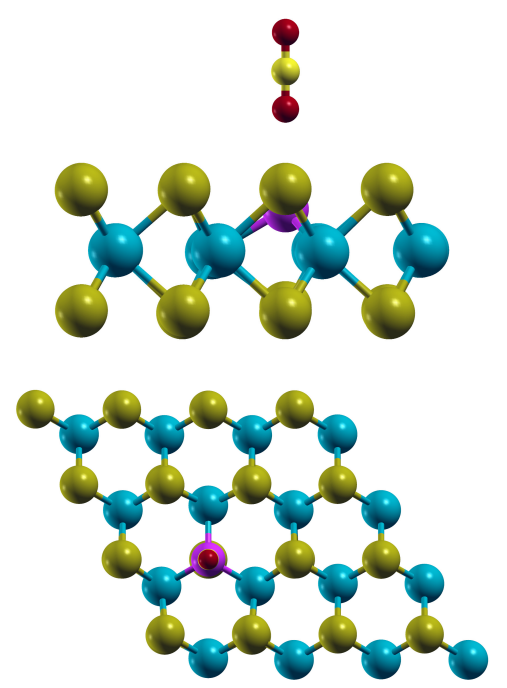

Figure S2: Initial configurations of $\mathrm{CO}_{2}$ before relaxation: (a) horizontal $\mathrm{C}$ on top of $\mathrm{X}$, (b) horizontal $\mathrm{O}$ on top of $\mathrm{X}$, and (c) vertical $\mathrm{C}$ on top of $\mathrm{X}$. 

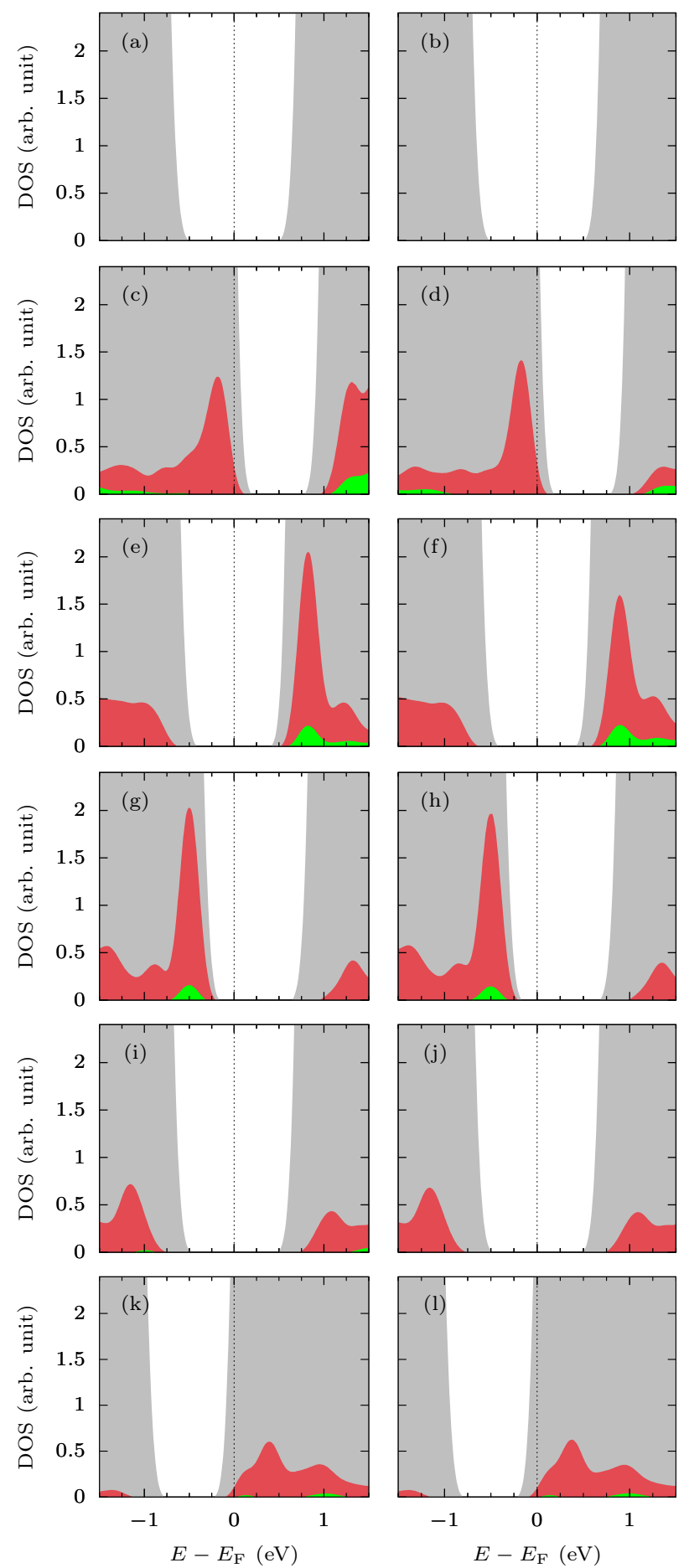

Figure S3: DOS contours of (a,b) MoTe 2 , (c,d) Al-MoTe $2,(e, f) S i-M_{0} \mathrm{Te}_{2},(\mathrm{~g}, \mathrm{~h}) \mathrm{P}-\mathrm{MoTe}_{2},(\mathrm{i}, \mathrm{j}) \mathrm{S}-\mathrm{MoTe}_{2}$, and (k,l) Cl-MoTe 2 . Left hand side figures represent pre-adsorption DOS, while the right hand side figures the DOS post CO adsorption (the lowest energy configuration). Gray contours represent the total DOS, while red and green the partial DOS of $\mathrm{p}$ and s orbitals of $\mathrm{X}$. 